\title{
Glycemic control after switching to faster aspart in adults with type 1 diabetes
}

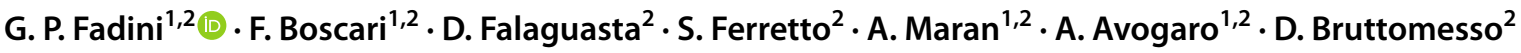

Received: 25 November 2021 / Accepted: 13 January 2022 / Published online: 1 February 2022

(c) The Author(s) 2022

\begin{abstract}
Aims Post-prandial hyperglycemia remains an unmet need in the management of type 1 diabetes (T1D). In randomized trials, faster insulin aspart (FIA) showed modest but significant reductions of glycemic spikes after meals. Whether such benefit is evident in routine clinical practice is unclear.

Methods We analyzed data of patients with T1D at the time they switched from a prior bolus insulin to FIA and at the first available follow-up. The primary endpoint was the change in the time spent in hyperglycemia $>250 \mathrm{mg} / \mathrm{dl}$ during daytime from flash glucose monitoring (FGM). Secondary outcomes included the change in HbA1c, body weight, insulin dose and other FGM metrics.

Results We included 117 patients with T1D on multiple daily injections who switched to FIA, 57 of whom had data from FGM. Patients were 41-year-old, 51.3\% men, with 19.3 years diabetes duration and a baseline HbA1c of $7.7 \%$ (60 mmol/ mol). Mean observation time was 4.3 months. After switching to FIA, HbA1c declined by $0.1 \%(1 \mathrm{mmol} / \mathrm{mol})$ only in patients with baseline $\mathrm{HbA} 1 \mathrm{c}>7.0 \%(53 \mathrm{mmol} / \mathrm{mol})$. Time spent in hyperglycemia $>250 \mathrm{mg} / \mathrm{dl}$ during daytime was significantly reduced from 14.8 to $11.9 \%$ ( $p=0.006)$. Time in range improved from 48.3 to $51.0 \%$ ( $p=0.028)$. Results were consistent across various patient characteristics.

Conclusions Under routine care, patients with T1D who switched to FIA experienced a reduction in the time spent in hyperglycemia $>250 \mathrm{mg} / \mathrm{dl}$ during daytime and an increase in time in range. These improvements may be due to better control of post-prandial hyperglycemia, as observed in trials.
\end{abstract}

Keywords Post-prandial hyperglycemia $\cdot$ Time in range $\cdot$ Observational $\cdot$ Bolus insulin

\section{Introduction}

In people with type 1 diabetes (T1D), post-prandial glucose excursions contribute to increasing glucose variability and decreasing time in range (TIR). This is demonstrated by studies on a dedicated algorithm to control post-prandial glucose with closed loop insulin delivery (1) and by studies showing post-prandial glucose control with a sodiumglucose co-transporter inhibitor (2).

G. P. Fadini

gianpaolo.fadini@unipd.it

1 Department of Medicine - DIMED, Division of Metabolic Disease, University of Padova, Via Giustiniani 2, 35128 Padua, Italy

2 Division of Metabolic Disease, University Hospital of Padova, Padua, Italy
Early ( $1 \mathrm{~h}$ ) post-prandial hyperglycemic spikes emerge as better determinant of metabolic dysregulation and vascular alterations than later ( $2 \mathrm{~h}$ ) glycemic values (3). Post-prandial hyperglycemia also worsens quality of life and is associated with loss of productivity (4-6). Therefore, mitigating post-prandial hyperglycemia is one of the aims of T1D glycemic management. To this end, interventions that approximate physiological post-prandial responses should actively be sought to reduce the risk of complications (7). Despite decades of optimization of basal-bolus insulin therapy, handling of post-prandial hyperglycemia with insulin injections remains an unmet need (8).

Faster insulin aspart (FIA) is a modified formulation of aspart with excipients that allow faster absorption of insulin monomers from the subcutaneous depot (9). The resulting anticipated $\mathrm{T}_{\max 50 \%}$ and increased early exposure $\left(\mathrm{AUC}_{0-30 \mathrm{~min}}\right)$ grant a greater glucose-lowering effect within 30 min after injection (10). In a meta-analysis of randomized 
controlled trials (RCTs), use of FIA as compared to insulin aspart among individuals with T1D achieved a modest but significant reduction in $\mathrm{HbA1c}(-0.08 \%)$ and a reduction in $1 \mathrm{~h}$ glucose excursion after a meal test $(-0.9 \mathrm{mmol} / \mathrm{L}$; $16 \mathrm{mg} / \mathrm{dl}$ ) (11). These effects are expected to improve TIR, defined as the time a patient spends in a given glycemic interval (usually $70-180 \mathrm{mg} / \mathrm{dl}$ ). TIR is emerging as a novel metric of glucose control beyond HbA1c (12). Due to hyperand hypoglycemic excursions, TIR can vary substantially for any given $\mathrm{HbAlc}$ value, implying that $\mathrm{HbA1c}$ can be misleading when used as the sole metric to judge glucose control (13). In fact, in people with T1D, TIR is associated with the risk of microvascular complications and provides incremental value when added to HbA1c to predict complications (14).

The widespread availability of flash glucose monitoring (FGM) among people with T1D allows an unprecedented opportunity to demonstrate early post-prandial hyperglycemia and assess TIR in routine clinical practice $(15,16)$. This also enables the real-world evaluation of new therapies, like FIA, that are expected to blunt glycemic excursions. To date, the published real-world experience with FIA in T1D is limited to results of the for-profit, multicenter, single-arm, non-interventional GoBolus study (17). Among 243 middleaged (50 year) patients with T1D since about 19 years and a baseline $\mathrm{HbA} 1 \mathrm{c}$ of $8.1 \%$ (65 mmol/mol), TIR improved from 46.9 to $50.1 \%$, due to a reduction in the time spent in hyperglycemia and no change in the time spent in hypoglycemia.

In the present study, we wished to confirm RCT findings and prior real-world experience on the effectiveness of FIA in reducing hyperglycemia and improving TIR. To this end, we performed a retrospective cohort study under free-living conditions, by collecting clinical data and, when available, FGM data from patients with T1D who switched from other bolus insulins to FIA.

\section{Methods}

\section{Study design and data source}

This was a retrospective, observational study with longitudinal data collection. The study was conducted in agreement with the principles of the declaration of Helsinki. In accordance to national regulations on retrospective studies, the protocol was cleared to by the Ethical Committee of the University Hospital of Padova (prot. no. 177n/AO/21). Patients provided written informed consent for the re-use of routinely collected clinical data for research purposes.

The source of data for this study was the electronic chart system of the diabetes outpatient clinic of the University Hospital of Padova, which stores information on all consecutive visits of all patients attending the clinic, including demographics, anthropometrics, lab exams, complications, and therapies. The data collection period was from April 2018 to March 2020.

\section{Patients}

Inclusion criteria were as follows: a diagnosis of T1D since at least one year; continuous use of basal-bolus insulin since at least 1 year; a switch from aspart, lispro or glulisine to FIA; availability of at least one follow-up examination after a minimum of 2 months and a maximum of 9 months since index date; still being on FIA at follow-up. The index date was set as the date patients initiated FIA. Date of the followup examination was set as the date patients re-accessed the clinic (2-9 months after index date) still being on FIA. We retrospectively ensured that no substantial change in dietary and exercise habits was requested from these patients. Patients were excluded if they were on continuous subcutaneous insulin infusion, or stopped FIA before returning to the clinic, or had missing data for evaluation of the outcomes.

Patients using FGM were a subgroup of the total population of included participants. To be included in this subgroup, patients needed to have complete data for 4 weeks before index data and 4 weeks before follow-up date, with sensor coverage of $90 \%$ or greater.

\section{Data collection}

We collected the following data for all patients: demographics (age, sex); diabetes duration; anthropometrics (height and weight for the calculation of BMI); data on concomitant risk factors (obesity, hypertension, dyslipidemia) and thyroid comorbidity; standard metrics of glucose control (HbAlc and fasting plasma glucose); complications (defined as coded in the electronic chart system, as described before (18)) with particular reference of micro- (retinopathy, nephropathy, neuropathy) and macroangiopathy (coronary, cerebral or peripheral); type and doses of previous bolus insulin; type and doses of ongoing basal insulin; other medications. Baseline data were collected closest to the index date $(<3$ months for laboratory data and $<6$ months for comorbidities).

For patients included in the FGM subgroup, we collected all FGM values at 15-min intervals from the cloud system (Libreview) connected to patients' smartphone applications. We calculated the following metrics from the 4 weeks preceding index date and the 4 weeks preceding follow-up date: average glucose, standard deviation, coefficient of variation, time in range $(70-180 \mathrm{mg} / \mathrm{dl})$, time spent in hypoglycemia $54-70 \mathrm{mg}$ and $<54 \mathrm{mg} / \mathrm{dl}$; time spent in hyperglycemia $180-250 \mathrm{mg} / \mathrm{dl}$ and $>250 \mathrm{mg} / \mathrm{dl}$. All metrics 
were re-calculated from raw data for day-and-night together and for the daytime (6am to $12 \mathrm{pm}$ ) and nighttime (0-6am) separately.

\section{Outcome variables}

We collected updated values for the following outcome variables for all patients, closest to the follow-up date but after index date: HbA1c, fasting glucose, body weight, bolus and basal insulin dose. In the entire study cohort, outcome measures were the change in $\mathrm{HbA1c}$, fasting glucose, weight and insulin doses. For patients in the FGM group, the primary endpoint was the change in the time spent in hyperglycemia $>250 \mathrm{mg} / \mathrm{dl}$, which is expected to best reflect hyperglycemic spikes occurring after meals and be ameliorated by FIA. All other sensor metrics were secondary outcomes.

\section{Statistical analysis}

Continuous variables are presented as mean (standard deviation), whereas categorical variables are presented as percentage. The change from baseline in continuous variables were assessed using paired Student's $t$ test. To adjust for different FIA exposure time (from baseline to follow-up), we used a generalized linear model for repeated measures. Statistical significance was accepted as $p<0.05$ and SPSS ver. 23 was used.

\section{Results}

\section{Patient characteristics}

A total of 191 patients initiating FIA between April 2018 and March 2020 were initially screened for available data. We excluded patients with type 2 diabetes, those using an insulin pump or who did not have valid follow-up data, and those who discontinued FIA. Thus, we finally included in the analysis 117 patients with T1D $(51.3 \%$ men $)$ who were, on average, 40.9 years old and had a diabetes duration of 19.4 years (Table 1). Baseline HbA1c was 7.7\% (60 mmol/ $\mathrm{mol}), 48.7 \%$ had at least one microvascular complication, while macrovascular complications were much rarer (6.8\%). As for the ongoing therapy at the time of switch, a similar number of patients were on insulin aspart (42.7\%) and lispro $(42.6 \%$,), while much less were on glulisine (15.4\%). Longacting insulin were distributed as follows: $27.4 \%$ were on glargine-100; $24.8 \%$ were on glargine-300; $47.9 \%$ were on degludec. A minority of patients were also on metformin or an SGLT-2 inhibitor. Fifty-seven patients were using a FGM and their characteristics are reported in Table 1.
Table 1 Clinical characteristics

\begin{tabular}{|c|c|c|c|}
\hline & All patients & SMBG & FGM \\
\hline Demographics & $N=117$ & $N=60$ & $N=57$ \\
\hline Age, years & $40.9(14.6)$ & $44.7(15.1)$ & $36.9(13.0)$ \\
\hline Sex male, $\%$ & 51.3 & 48.3 & 54.4 \\
\hline Diabetes duration, years & $19.4(11.8)$ & $21.2(11.5)$ & $17.3(11.6)$ \\
\hline \multicolumn{4}{|l|}{ Risk factors and comorbidities } \\
\hline Obesity, \% & 6.0 & 8.3 & 3.5 \\
\hline BMI, $\mathrm{kg} / \mathrm{m}^{2}$ & $24.2(3.6)$ & $24.4(3.8)$ & $24.1(3.5)$ \\
\hline Body weight, $\mathrm{kg}$ & $71.2(13.7)$ & $71.0(14.6)$ & $71.5(12.9)$ \\
\hline Hypertension, \% & 34.2 & 41.7 & 26.3 \\
\hline $\begin{array}{l}\text { Systolic blood pressure, } \mathrm{mm} \\
\mathrm{Hg}\end{array}$ & $131.4(16.1)$ & $133.7(18.9)$ & $128.9(12.1)$ \\
\hline $\begin{array}{l}\text { Diastolic blood pressure, } \\
\mathrm{mm} \mathrm{Hg}\end{array}$ & $78.1(9.4)$ & $78.0(10.8)$ & $78.2(7.7)$ \\
\hline Dyslipidemia, $\%$ & 35.0 & 33.3 & 36.8 \\
\hline Total cholesterol, mg/dl & $177.4(29.4)$ & $173.8(25.7)$ & $181.7(32.9)$ \\
\hline HDL cholesterol, mg/dl & $62.6(15.1)$ & $62.0(14.3)$ & $63.4(16.0)$ \\
\hline Triglycerides, mg/dl & $81.5(41.3)$ & $83.4(40.3)$ & $79.3(42.8)$ \\
\hline LDL cholesterol, mg/dl & $98.5(26.6)$ & $95.1(24.7)$ & $102.4(28.3)$ \\
\hline Thyroid disease, $\%$ & 14.5 & 13.3 & 15.8 \\
\hline \multicolumn{4}{|l|}{ Glucose control } \\
\hline Fasting plasma glucose, $\mathrm{mg} / \mathrm{dl}$ & $163.6(67.1)$ & $161.1(60.5)$ & $166.8(76.0)$ \\
\hline $\mathrm{HbA} 1 \mathrm{c}, \%$ & $7.7(0.8)$ & $7.7(0.8)$ & $7.7(0.8)$ \\
\hline \multicolumn{4}{|l|}{ Complications } \\
\hline Cardiovascular disease, $\%$ & 1.7 & 3.3 & 0.0 \\
\hline Chronic kidney disease, $\%$ & 3.2 & 5.7 & 0.0 \\
\hline $\mathrm{eGFR}, \mathrm{ml} / \mathrm{min} / 1.73 \mathrm{~m}^{2}$ & $102.0(20.1)$ & $98.9(21.8)$ & $105.9(17.2)$ \\
\hline Micro-/macro-albuminuria, \% & 6.0 & 3.3 & 8.8 \\
\hline Retinopathy, \% & 38.0 & 41.0 & 34.4 \\
\hline Neuropathy, \% & 41.8 & 48.3 & 34.6 \\
\hline Any macroangiopathy, $\%$ & 6.8 & 10.0 & 3.5 \\
\hline Any microangiopathy, $\%$ & 48.7 & 53.1 & 43.9 \\
\hline \multicolumn{4}{|l|}{ Previous bolus insulin } \\
\hline Aspart, \% & 42.7 & 46.7 & 40.4 \\
\hline Lispro, \% & 43.6 & 45.0 & 38.5 \\
\hline Glulisine, $\%$ & 15.4 & 8.3 & 22.8 \\
\hline \multicolumn{4}{|l|}{ Basal insulin } \\
\hline Glargine-100, \% & 27.4 & 21.7 & 33.3 \\
\hline Glargine- $300, \%$ & 24.8 & 22.3 & 26.3 \\
\hline Degludec-100, \% & 47.9 & 55.0 & 40.4 \\
\hline \multicolumn{4}{|l|}{ Other drugs } \\
\hline Metformin, $\%$ & 7.7 & 8.3 & 7.0 \\
\hline SGLT2i, \% & 3.4 & 3.3 & 3.5 \\
\hline RAS blockers, $\%$ & 10.3 & 10.0 & 10.5 \\
\hline Statin, $\%$ & 17.1 & 21.7 & 12.3 \\
\hline Anti-platelet agents & 1.7 & 1.7 & 1.8 \\
\hline
\end{tabular}

$B M I$ body mass index, $H D L$ high density cholesterol, $L D L$ low density cholesterol, eGFR estimated glomerular filtration rate, $S G L T 2 i$ sodium-glucose co-transporter-2 inhibitors, $R A S$ renin angiotensin system. Data are presented as mean (standard deviation) or as percentage 


\section{Change in clinical-laboratory parameters}

In the entire cohort, patients were re-assessed a median of 4.2 months (IQR 3.4-5.3) after initiation of FIA (index date). We observed no change in $\mathrm{HbAlc}$, fasting glucose or body weight. While bolus insulin doses remained unchanged, basal insulin dose slightly but significantly increased by an average $0.3 \mathrm{IU}$ (Table 2). The change in $\mathrm{HbA1c}$ was statistically significant only among patients with a baseline $\mathrm{HbA} 1 \mathrm{c}$ above $7.0 \%$ (53 $\mathrm{mmol} / \mathrm{mol}):-0.09$; $95 \% \mathrm{CI}-0.004 \%$ to $-0.18 \%$ (equal to $-0.9 \mathrm{mmol} / \mathrm{mol} ; 95 \%$ CI -0.04 to -1.8$)$.

\section{Change in sensor metrics}

In the subgroup of patients using FGM (all with first-generation sensors), the median follow-up time was 4.1 months (IQR 3.4-5.0). The change in HbAlc in this subgroup of patients was similar to that observed in the entire population, as the effect was significant only for patients with baseline $\mathrm{HbA} 1 \mathrm{c}>7.0 \%$ ( $53 \mathrm{mmol} / \mathrm{mol}):-0.09 ; 95 \%$ CI $-0.0001 \%$ to $-0.18 \%$ (equal to $-0.9 \mathrm{mmol} / \mathrm{mol} ; 95 \% 0-01$ to -1.8 ).

Table 3 and Fig. 1A show the change in glucose sensor metrics We observed a significant reduction in average glucose levels during the entire time of the day, which was mostly attributable to a reduction in average glucose during daytime (from mean \pm SD $162.2 \pm 34.7$ to $155.0 \pm 27.2$; $p=0.016$ ). Nighttime improvement in average glucose was smaller and not statistically significant. The time spent in hyperglycemia $>250 \mathrm{mg} / \mathrm{dl}$ during day-and-night decreased significantly, which was attributable to a reduction during daytime (from $14.8 \pm 12.8 \% \%$ to $11.9 \pm 9.7 \% ; p=0.006$ ). This finding was confirmed after adjusting for FIA exposure time (from $15.4 \%$ to $11.3 \% ; p<0.001$ ).

The improvement in nighttime spent in hyperglycemia $>250 \mathrm{mg} / \mathrm{dl}$ was quantitatively similar but not statistically significant $(p=0.07)$ due to greater variability (SD) of the effect. Time spent in hypoglycemia did not change. An increase in time in range was observed, which was significant during daytime (from $47.8 \pm 17.6 \%$ to $50.8 \pm 14.7$; $p=0.020$ ) but not during nighttime (Fig. 1B). Metrics of glucose variability (standard deviation and coefficient of variation) remained unchanged.

We then stratified patients according to key clinical characteristics, including age, sex, diabetes duration, baseline HbA1c, presence/absence of microangiopathy and type of prior insulin therapy. The change in time spent in hyperglycemia $>250 \mathrm{mg} / \mathrm{dl}$ was consistent in subgroups and not significantly modified by any of these baseline clinical characteristic or duration of exposure (Fig. 2).

Table 2 Change in clinical parameters

\begin{tabular}{llll}
\hline Variable & Baseline & Follow-up & $p$ value \\
\hline HbA1c, \% & $7.7(0.8)$ & $7.6(0.8)$ & 0.300 \\
Fasting glucose, $\mathrm{mg} / \mathrm{dl}$ & $163.6(67.1)$ & $168.4(72.1)$ & 0.474 \\
Body weight, $\mathrm{kg}$ & $71.2(13.6)$ & $71.2(13.8)$ & 0.788 \\
Basal insulin (mean daily dose), IU/kg & $0.27(0.11)$ & $0.28(0.10)$ & 0.023 \\
Basal insulin (mean daily dose), IU & $19.3(8.4)$ & $19.6(8.3)$ & 0.029 \\
Bolus insulin (mean daily dose), IU/kg & $0.33(0.15)$ & $0.32(0.15)$ & 0.783 \\
Bolus insulin (mean daily dose), IU & $23.0(10.9)$ & $23.0(11.4)$ & 0.949 \\
\hline
\end{tabular}

These endpoints have been analyzed in the entire population of 117 patients. Data are presented as mean (standard deviation)

Table 3 Metrics from the flash glucose monitoring system

\begin{tabular}{|c|c|c|c|c|c|c|c|c|c|}
\hline & \multicolumn{3}{|c|}{ Day and night } & \multicolumn{3}{|c|}{ Nightime (0:00-6:00am) } & \multicolumn{3}{|c|}{ Daytime (6:00am - 0:00) } \\
\hline & Baseline & Follow-up & $p$ value & Baseline & Follow-up & $p$ value & Baseline & Follow-up & $p$ value \\
\hline Mean, mg/dl & $163.7(33.8)$ & $157.0(26.1)$ & 0.021 & $169.7(39.0)$ & $164.1(30.8)$ & 0.131 & $162.2(34.7)$ & $155.0(27.2)$ & 0.016 \\
\hline $\mathrm{SD}, \mathrm{mg} / \mathrm{dl}$ & $76.6(21.1)$ & $75.1(19.7)$ & 0.243 & $69.3(20.8)$ & $67.6(20.6)$ & 0.504 & $77.5(22.6)$ & $75.8(20.6)$ & 0.198 \\
\hline $\mathrm{CV}, \%$ & $48.0(14.1)$ & $48.5(12.6)$ & 0.676 & $42.1(13.2)$ & $41.3(10.7)$ & 0.594 & $49.1(15.4)$ & $49.9(14.2)$ & 0.540 \\
\hline Very low, $\%<54 \mathrm{mg} / \mathrm{dl}$ & $2.8(2.5)$ & $2.9(1.9)$ & 0.621 & $3.5(3.8)$ & $3.5(3.1)$ & 0.985 & $2.6(2.5)$ & $2.8(2.0)$ & 0.517 \\
\hline Low, \% 54-69 mg/dl & $8.6(8.7)$ & $9.0(8.2)$ & 0.482 & $5.0(6.0)$ & $5.4(5.4)$ & 0.491 & $9.6(9.8)$ & $10.1(9.5)$ & 0.571 \\
\hline Range, $\% 70-180 \mathrm{mg} / \mathrm{dl}$ & $48.3(17.0)$ & $51.0(14.4)$ & 0.028 & $50.0(18.5)$ & $52.0(16.9)$ & 0.234 & $47.8(17.6)$ & $50.8(14.7)$ & 0.020 \\
\hline High, \% 181-250 mg/dl & $25.6(9.4)$ & $25.1(7.7)$ & 0.544 & $26.3(14.9)$ & $26.8(12.2)$ & 0.789 & $25.2(9.0)$ & $24.5(7.5)$ & 0.402 \\
\hline Very high, $\%>250 \mathrm{mg} / \mathrm{dl}$ & $14.7(12.1)$ & $12.0(9.5)$ & 0.005 & $15.2(15.2)$ & $12.4(11.4)$ & 0.070 & $14.8(12.8)$ & $11.9(9.7)$ & 0.006 \\
\hline
\end{tabular}

Data are presented as mean (standard deviation). $S D$ standard deviation, $C V$ coefficient of variation 
Fig. 1 Change in sensor metrics. A Time spent in the various glucose ranges before (pre) and after (post) switching to FIA. The metrics are calculated in the entire day, daytime and nighttime separately. B Changes in time spent in the various glucose range (same legend as in panel $\mathbf{A}$ ). ${ }^{*} p<0.05$
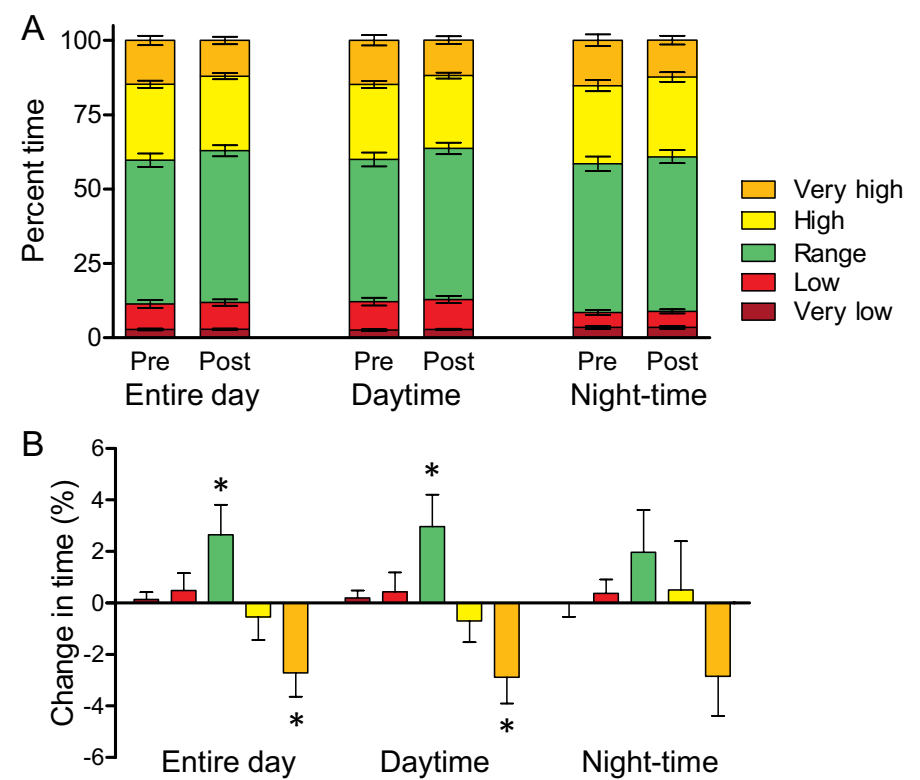

with a $64 \%$ increase in the relative risk of retinopathy and $40 \%$ increase in the relative risk of microalbuminuria (14, 21). Indeed, TIR is emerging as a novel metric that complements HbA1c in assessing the overall impact of diabetes therapies on glycemic control (12). It should be noted that no clinically evident benefit could be observed among patients who had a baseline $\mathrm{HbA} 1 \mathrm{c}$ value of $7 \%$ or lower and who were not using FGM.

Our study has typical limitations inherent to its retrospective design and real-world nature. The lack of a control group does not allow dissecting how much of the observed effect is due to the specific pharmacokinetics of FIA, or to random fluctuations, or to the change in therapy itself. In fact, any switch to a more modern therapy may elicit intrinsic improvements irrespectively of the true benefits of the new treatment. No benefit could be demonstrated for patients not wearing the FGM, for whom detailed data from self-monitoring of blood glucose (SMBG) were not available. In addition, we did not record how many correction boluses were the patients injecting at baseline and follow-up. Above all, we had no detailed information on the timing of the meals, on the timing of insulin injection with respect to the meal, and on meal composition. This prevented a formal evaluation of 1 -h or $2-\mathrm{h}$ post-prandial hyperglycemia. Though it is reasonable that glycemic spikes $>250 \mathrm{mg} / \mathrm{dl}$ are mainly due to the rapid post-prandial glucose surge, we acknowledge that the change in time spent with glucose value $>250 \mathrm{mg} / \mathrm{dl}$ may have other causes. The fact that glycemic improvement was more evident during daytime than during nighttime is consistent with a better coverage of postprandial hyperglycemia. The trend reduction in hyperglycemia $>250 \mathrm{mg} / \mathrm{dl}$ during nighttime may be a consequence of a better control of post-dinner hyperglycemia. Even if our 
Fig. 2 Subgroup analysis. Change in the percentage of time spent in very high glucose during daytime according to patient characteristics and duration of exposure. Data are presented as mean $(95 \% \mathrm{CI})$. $P$ values are reported for the comparison between subgroups defined by clinical variables

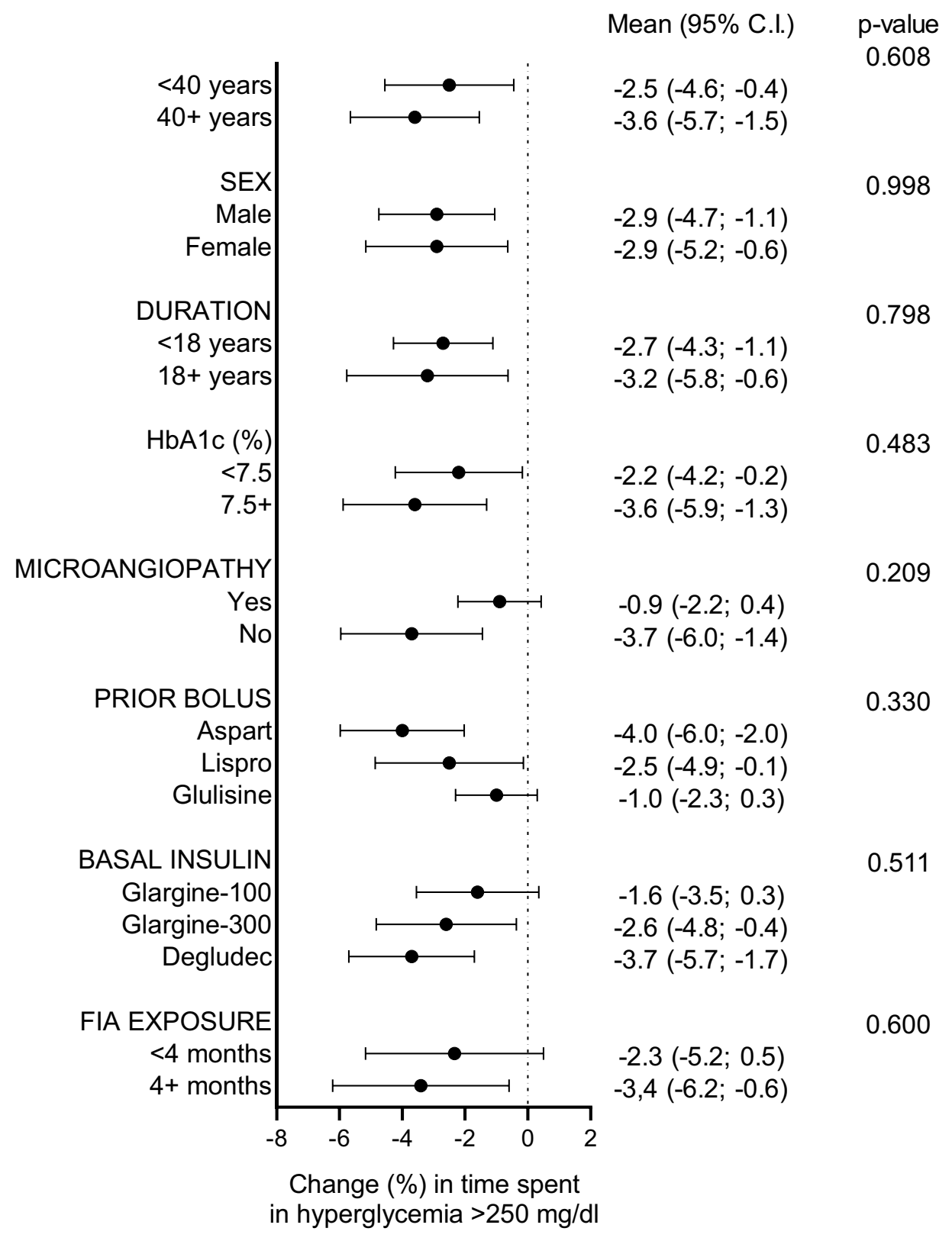

patients were always advised to inject bolus insulin before the meals (except when pre-prandial glucose is low), we cannot ensure that the changes we observe are due, at least in part, to the changes in the timing of bolus insulin injection. In other terms, similar results could be obtained by imposing an anticipation in the injection of other bolus insulins with respect to mealtime (22). Nonetheless, it is remarkable that, in free-living conditions and without any control over the timing of bolus injection, switch to FIA resulted in a significant reduction in the time spent with very high glucose values without changes in the time spent in hypoglycemia. Due to the purely retrospective nature of our study, we did not collect patient-reported outcomes, but we expect that limiting glycemic excursions could improve patients' satisfaction with regards to treatment (17). In addition, FIA may grant a more flexible bolus administration, which can be an added value for young people with T1D.

It is also important to note that, in the absence of clinically meaningful improvements in $\mathrm{HbA} 1 \mathrm{c}$, the benefit of switching to FIA was observed only among T1D patients wearing the FGM system. Indeed, the widespread use of FGM, especially among people with T1D, today allows an unprecedented opportunity to analyze glucose trends and identify possible solutions. For example, a steep rise in glucose within the first 30-60 min after a meal can hardly be resolved by increasing bolus insulin dose, especially when the glucose values return to target range 2-3 h after the meal. In these cases, switch to FIA can 
yield a better synchronization of insulin action with postprandial glucose appearance and reduce glycemic excursions. Consistently, we observed reductions in glycemic values $>250 \mathrm{mg} / \mathrm{dl}$ without any change in the dose of bolus insulin. On the other side, the significant increase in basal insulin dose, not accompanied by any change in the time spent in hypoglycemia, possibly reflects a more confident self-titration. Anyway, we acknowledge that such change was very small ( $<1.0$ IU/day) and unlikely to be clinically relevant. It should also be noted that we did not record information on the reasons driving the switch from prior bolus insulins to FIA, thereby making it impossible to rule out selection bias and assess generalizability of our finding. Finally, we only collected information at the first available follow-up visit after initiation of FIA and, therefore, cannot draw conclusions on whether and how long the observed improvements in glycemic control persist over time.

Notwithstanding such limitations, we believe our data provide a confirmation that the benefits of FIA demonstrated in RCTs can also be observed during the routine care of patients with T1D wearing a FGM system. This technology now enables enhanced opportunities of detecting glucose trends and applying the best solution for a patient-centric approach.

\section{Acknowledgements None.}

Author contributions Study design: GPF, AA, DB. Data collection and analysis: GPF, FB, DF, AM, SF. Manuscript writing: GPF, DB. Manuscript revision: FB, DF, SF; AA, AM. All named authors meet the International Committee of Medical Journal Editors (ICMJE) criteria for authorship for this article, take responsibility for the integrity of the work as a whole, and have given their approval for this version to be published.

Funding None.

Data availability Original data used in this manuscript are available from the corresponding author at a reasonable request.

\section{Declarations}

Conflict of interest GPF received grants, consultancy or lecture fees from Abbott, AstraZeneca, Boehringer, Lilly, Merck-Sharp-Dome, Mundipharma, Novo Nordisk, Novartis, Sanofi, Servier, Takeda. FB have received lecture fees from Abbott and Roche, Eli Lilly, Lifescan, Sanofi. AA received research grants, lecture or advisory board fees from: Merck-Sharp-Dome, AstraZeneca, Novartis, BoehringerIngelheim, Sanofi, Mediolanum, Janssen, Novo Nordisk, Lilly, Servier, Takeda. DB have received lecture fees from Abbott, Lilly, Roche, Sanofi and advisory board fees from AstraZeneca, Becton Dickinson, Sanofi. DF, SF, and AM have nothing to disclose. The authors declare that they have no known competing financial interests or personal relationships that could have appeared to influence the work reported in this paper. GPF is an Associate Editor for the Journal of Endocrinological Investigations.
Ethical approval The study was conducted in agreement with the principles of the declaration of Helsinki. The protocol was cleared to by the Ethical Committee of the University Hospital of Padova (prot. no. $177 \mathrm{n} / \mathrm{AO} / 21)$.

Informed Consent Patients provided written informed consent.

Open Access This article is licensed under a Creative Commons Attribution 4.0 International License, which permits use, sharing, adaptation, distribution and reproduction in any medium or format, as long as you give appropriate credit to the original author(s) and the source, provide a link to the Creative Commons licence, and indicate if changes were made. The images or other third party material in this article are included in the article's Creative Commons licence, unless indicated otherwise in a credit line to the material. If material is not included in the article's Creative Commons licence and your intended use is not permitted by statutory regulation or exceeds the permitted use, you will need to obtain permission directly from the copyright holder. To view a copy of this licence, visit http://creativecommons.org/licenses/by/4.0/.

\section{References}

1. Rossetti P, Quiros C, Moscardo V, Comas A, Gimenez M, Ampudia-Blasco FJ, Leon F, Montaser E, Conget I, Bondia J, Vehi J (2017) Closed-loop control of postprandial glycemia using an insulin-on-board limitation through continuous action on glucose target. Diabetes Technol Ther 19:355-362

2. Danne T, Cariou B, Buse JB, Garg SK, Rosenstock J, Banks P, Kushner JA, McGuire DK, Peters AL, Sawhney S, Strumph P (2019) Improved time in range and glycemic variability with sotagliflozin in combination with insulin in adults with type 1 diabetes: a pooled analysis of 24-week continuous glucose monitoring data from the intandem program. Diabetes Care 42:919-930

3. Ceriello A (2017) Targeting one-hour postmeal glucose: is it time for a paradigm switch in diabetes management? Diabetes Technol Ther 19:493-497

4. Heller S, Meneghini L, Nikolajsen A, Kragh N, Lewis HB, Saretsky T, Kosmas CE, Lloyd A (2019) Towards a better understanding of postprandial hyperglycemic episodes in people with diabetes: impact on daily functioning. Curr Med Res Opin 35:525-533

5. Brod M, Nikolajsen A, Weatherall J, Pfeiffer KM (2016) Understanding post-prandial hyperglycemia in patients with type 1 and type 2 diabetes: a web-based survey in Germany, the UK, and USA. Diabetes Ther 7:335-348

6. Brod M, Nikolajsen A, Weatherall J, Pfeiffer KM (2016) The economic burden of post-prandial hyperglycemia (PPH) among people with type 1 and type 2 diabetes in three countries. Diabetes Ther 7:75-90

7. Madsbad S (2016) Impact of postprandial glucose control on diabetes-related complications: How is the evidence evolving? J Diabetes Complications 30:374-385

8. Owens DR, Bolli GB (2020) The continuing quest for better subcutaneously administered prandial insulins: a review of recent developments and potential clinical implications. Diabetes Obes Metab 22:743-754

9. Kildegaard J, Buckley ST, Nielsen RH, Povlsen GK, Seested T, Ribel U, Olsen HB, Ludvigsen S, Jeppesen CB, Refsgaard HHF, Bendtsen KM, Kristensen NR, Hostrup S, Sturis J (2019) Elucidating the mechanism of absorption of fast-acting insulin aspart: the role of niacinamide. Pharm Res 36:49

10. Heise T, Pieber TR, Danne T, Erichsen L, Haahr H (2017) A pooled analysis of clinical pharmacology trials investigating the 
pharmacokinetic and pharmacodynamic characteristics of fastacting insulin aspart in adults with type 1 diabetes. Clin Pharmacokinet 56:551-559

11. Pal R, Banerjee M, Bhadada SK (2021) Glycaemic efficacy and safety of mealtime faster-acting insulin aspart administered by injection as compared to insulin aspart in people with diabetes mellitus: A meta-analysis of randomized controlled trials. Diabet Med 38:e14515

12. Battelino T, Danne T, Bergenstal RM, Amiel SA, Beck R, Biester T, Bosi E, Buckingham BA, Cefalu WT, Close KL, Cobelli C, Dassau E, DeVries JH, Donaghue KC, Dovc K, Doyle FJ 3rd, Garg S, Grunberger G, Heller S, Heinemann L, Hirsch IB, Hovorka R, Jia W, Kordonouri O, Kovatchev B, Kowalski A, Laffel L, Levine B, Mayorov A, Mathieu C, Murphy HR, Nimri R, Norgaard K, Parkin CG, Renard E, Rodbard D, Saboo B, Schatz D, Stoner K, Urakami T, Weinzimer SA, Phillip M (2019) Clinical targets for continuous glucose monitoring data interpretation: recommendations from the international consensus on time in range. Diabetes Care 42:1593-1603

13. Beck RW, Connor CG, Mullen DM, Wesley DM, Bergenstal RM (2017) The Fallacy of average: how using hbalc alone to assess glycemic control can be misleading. Diabetes Care 40:994-999

14. Beck RW, Bergenstal RM, Riddlesworth TD, Kollman C, Li Z, Brown AS, Close KL (2019) Validation of time in range as an outcome measure for diabetes clinical trials. Diabetes Care 42:400-405

15. Deshmukh H, Wilmot EG, Gregory R, Barnes D, Narendran P, Saunders S, Furlong N, Kamaruddin S, Banatwalla R, Herring R, Kilvert A, Patmore J, Walton C, Ryder REJ, Sathyapalan T (2020) Effect of Flash Glucose Monitoring on Glycemic Control, Hypoglycemia, Diabetes-Related Distress, and Resource Utilization in the Association of British Clinical Diabetologists (ABCD) Nationwide Audit. Diabetes Care 43:2153-2160

16. Dunn TC, Xu Y, Hayter G, Ajjan RA (2018) Real-world flash glucose monitoring patterns and associations between self-monitoring frequency and glycaemic measures: A European analysis of over 60 million glucose tests. Diabetes Res Clin Pract 137:37-46
17. Danne T, Axel Schweitzer M, Keuthage W, Kipper S, Kretzschmar Y, Simon J, Wiedenmann T, Ziegler R (2021) Impact of fastacting insulin aspart on glycemic control in patients with type 1 diabetes using intermittent-scanning continuous glucose monitoring within a real-world setting: The GoBolus study. Diabetes Technol Ther 23:203-212

18. Fadini GP, Zatti G, Consoli A, Bonora E, Sesti G, Avogaro A (2017) Rationale and design of the DARWIN-T2D (DApagliflozin Real World evIdeNce in Type 2 Diabetes): A multicenter retrospective nationwide Italian study and crowdsourcing opportunity. Nutr Metab Cardiovasc Dis 27:1089-1097

19. Russell-Jones D, Bode BW, De Block C, Franek E, Heller SR, Mathieu C, Philis-Tsimikas A, Rose L, Woo VC, Osterskov AB, Graungaard T, Bergenstal RM (2017) Fast-acting insulin aspart improves glycemic control in basal-bolus treatment for type 1 diabetes: results of a 26-week multicenter, active-controlled, treat-totarget, randomized, parallel-group trial (onset 1). Diabetes Care 40:943-950

20. DeFronzo RA, Stonehouse AH, Han J, Wintle ME (2010) Relationship of baseline HbA1c and efficacy of current glucose-lowering therapies: a meta-analysis of randomized clinical trials. Diabet Med 27:309-317

21. Lu J, Ma X, Zhou J, Zhang L, Mo Y, Ying L, Lu W, Zhu W, Bao Y, Vigersky RA, Jia W (2018) Association of time in range, as assessed by continuous glucose monitoring, with diabetic retinopathy in type 2 diabetes. Diabetes Care 41:2370-2376

22. Slattery D, Amiel SA, Choudhary P (2018) Optimal prandial timing of bolus insulin in diabetes management: a review. Diabet Med $35: 306-316$

Publisher's Note Springer Nature remains neutral with regard to jurisdictional claims in published maps and institutional affiliations. 